gained proportionally greater benefit from FPSM minus FP compared to smokers: $1.4 \mathrm{dd}$ ( $95 \%$ CI 0.01 to 2.8 ), $\mathrm{p}=0.047$. Similar changes were observed in $\mathrm{FEV}_{1}$ and IOS, and a similar but nonsignificant trend was seen with AHR to mannitol.

Conclusion Combination FPSM confers greater improvements in AHR and airway caliber in smoking asthmatics, as compared to double the dose of FP alone. It is likely that in the face of the relative steroid resistance, the smooth muscle stabilisation conferred by SM becomes of greater clinical importance.

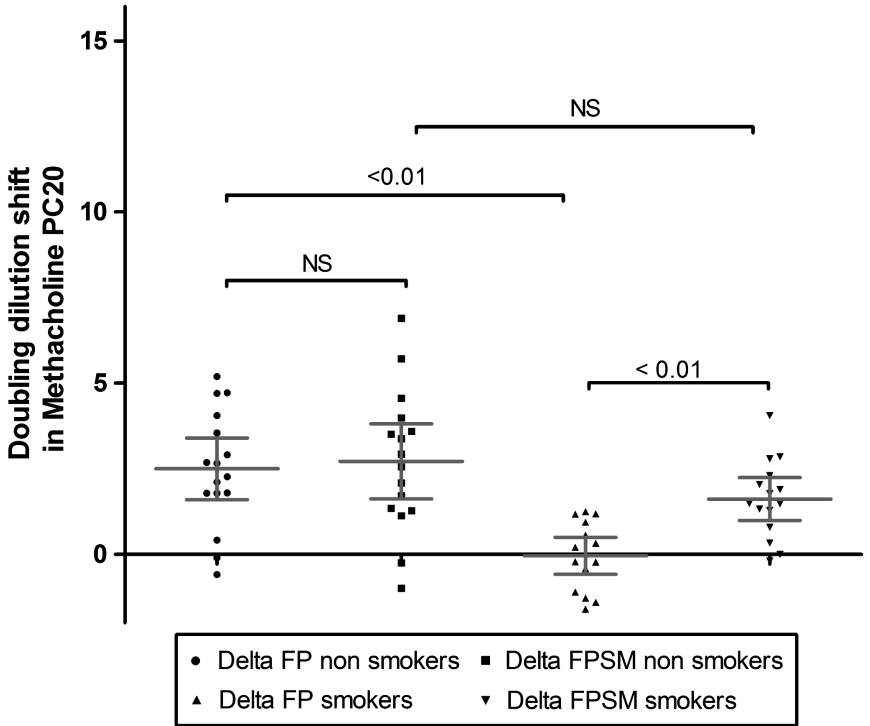

\section{P173 MANAGEMENT OF SPUTUM EOSINOPHIL-NEGATIVE PATIENTS IN A SEVERE ASTHMA CLINIC}

doi:10.1136/thx.2010.151043.24

G Tavernier, C Pris-Picard, R Gore, R Niven. University of Manchester, Wythenshawe Hospital, Manchester, UK

Asthma is a heterogeneous disease that requires physicians to further phenotype their patients in order to offer carefully customised treatment. Among recent and rapidly evolving tools at clinicians' disposal are sputum analysis for several markers of inflammation, particularly sputum eosinophil count has become a marker widely used. Sputum differential cell counting was introduced in our severe asthma clinic to help further phenotype our patients with a view to first reducing sputum eosinophils below $3 \%$ by augmenting anti-inflammatory therapy, and attempting steroid withdrawal once subjects became sputum eosinophil negative (E-). This report investigates its impact on the management of patients with negative sputum eosinophilia at baseline. To date, 264 patients have been investigated for sputum eosinophils, using induction with nebulised sodium chloride if necessary and suitable. Of these, $71 \mathrm{had}$ 2 or more valid results enabling us to assess how these subjects were managed following their initial negative cell count results. Out of 42 patients initially $\mathrm{E}-, 36$ remained $\mathrm{E}-$. Twenty-seven were offered a trial of reduction in steroid therapy:

2 patients stopped IM triamcinolone (both remained $\mathrm{E}-$ );

20 patients had decreased oral prednisolone treatment (15 remained $\mathrm{E}-$ )

5 patients decreased inhaled steroid therapy (all remained E-).

Despite negative sputum at baseline, five patients were given a trial of triamcinolone, to confirm their absence of response to steroids, of these 4 remained $\mathrm{E}-$, whilst surprisingly 1 patient became $\mathrm{E}+$.

In those $\mathrm{E}$ - at baseline, $64 \%$ had a reduction in steroid therapy. Of these more than $80 \%$ remained $\mathrm{E}-$, despite reduced therapy, whilst $20 \%$ had recurrence of $\mathrm{E}+$. For $83 \%$ of those who became $\mathrm{E}+$, there were strong indications that their initial dose of maintenance oral steroids was probably already optimal. It is surprising that five patients were offered a trial of IM triamcinolone despite initial negative sputum eosinophils. However, it has been recently reported that increased steroid therapy in sputum non-eosinophilic patients still had positive impact on reducing markers of inflammation different from sputum eosinophils. It was possible to reduce steroid therapy without losing asthma control for $80 \%$ of patients initially E-

\section{P174 IDENTIFYING NON-ADHERENCE WITH ASTHMA MEDICATION AND THE RELATIONSHIP TO CLINICAL OUTCOMES AMONGST ADULTS WITH DIFFICULT-TO- CONTROL ASTHMA}

doi:10.1136/thx.2010.151043.25

${ }^{1} \mathrm{~A}$ C Murphy, ${ }^{2} \mathrm{~A}$ Proeschel, ${ }^{1} \mathrm{M}$ E Linnett, ${ }^{3} \mathrm{C}$ E Brightling, ${ }^{3} \mathrm{~A} J$ Wardlaw, ${ }^{3} \mathrm{I}$ D Pavord, ${ }^{3} \mathrm{P}$ Bradding, ${ }^{3} \mathrm{R}$ H Green. ${ }^{1}$ University Hospitals of Leicester NHS Trust, Leicester, UK; ${ }^{2}$ School of Pharmacy, Grenoble, France; ${ }^{3}$ Institute for Lung Health, Leicester, UK

Background The failure of patients to adhere to prescribed medication regimens is well documented. The clinical effects of nonadherence can include treatment failure, unnecessary, potentially dangerous and costly intensification of therapy, complications and hospitalisations. The extent of non-adherence and the clinical implications in difficult-to-treat asthma were audited.

Method A total of 161 adult asthma patients attending a difficult asthma clinic during July/August 2009 were included in the audit. GPs retrospective prescription refill data for asthma medicines, patient demographics and clinical outcome data were collated. The medication adherence ratio was calculated as the number of doses refilled/ number of doses prescribed $\times 100$ for a mean duration of 12 months. Adherence was defined as adequate if the ratio was $\geq 80 \%$.

Results Prescription refill data for 132 patients were available (82\%), and 115 patients were included in the audit. Poor adherence was identified in $75 / 115$ patients $(65.2 \%)$ on inhaled corticosteroids (ICS) overall - 64/101 (63.4\%) taking combined ICS and long acting $\beta_{2}$ agonist (LABA) inhalers and 11/14 (78.6\%) patients taking separate ICS and LABA inhalers $(p=0.24)$. In the 14 patients using separate ICS and LABA, adherence to the LABA (50\%) was significantly better than adherence to the ICS $(14.3 \%)(\mathrm{p}=0.043)$. Patients with poor adherence to ICS had a lower post-bronchodilator $\mathrm{FEV}_{1}$ (75.4 (20.9) vs 84.3 (23.5), $\mathrm{p}=0.049)$ and higher sputum eosinophil counts $(4.6(0.66) \%$ vs 2.3 $(0.54) \%, p=0.05)$ than those with adequate ICS adherence. There were no significant differences in age, gender, racial origin, smoking history or courses of rescue oral prednisolone between these two groups. Patients with poor ICS adherence were more likely to have been ventilated for asthma $(19.2 \%$ vs $2.6 \%, p=0.02)$. In a multivariate logistic regression model, the adherence ratio was the only independent predictor of previous need for ventilation for acute severe asthma $(p=0.008)$. Thus for each $10 \%$ decrease in adherence to ICS, the estimated odds of having been ventilated for asthma increased by 1.85 times.

Conclusion The majority of patients with difficult-to-control asthma are non-adherent with their asthma medication. Patients using separate ICS and LABA inhalers use the LABA more than the ICS Non-adherence is correlated with several poor clinical outcomes.

\section{P175 CROSS-SECTIONAL AND LONGITUDINAL RELATIONSHIPS OF SELF-MANAGEMENT BEHAVIOURS AND OTHER PSYCHOLOGICAL FACTORS WITH OUTCOMES IN PATIENTS WITH SEVERE ASTHMA}

doi:10.1136/thx.2010.151043.26

${ }^{1} \mathrm{~J}$ R Smith, ${ }^{2} \mathrm{M}$ J Noble, ${ }^{1} \mathrm{~B}$ D W Harrison, ${ }^{1} \mathrm{M}$ Adams. ${ }^{1}$ School of Medicine, Health Policy \& Practice; University of East Anglia, Norwich, UK; ${ }^{2}$ Acle Medical Centre, Acle Norfolk, UK

Background Psychosocial factors are associated with various manifestations of severe asthma. Wider research and theory highlight 